\title{
Estudo de caso sobre o olhar do estudante do ensino médio técnico para a disciplina de sociologia
}

\author{
Silvana Colombelli Parra Sanches
}

\section{Resumo}

Esta pesquisa permite refletir sobre o olhar do (a) estudante para a disciplina de sociologia. Os sujeitos da pesquisa incluem-se no grupo social da juventude do campo, a pesquisa é qualitativa e o instrumento de coleta de dados vincula-se ao processo avaliativo. Assim, trata-se de uma investigação produzida em sala de aula, que se situa no campo do professor observador de suas práticas, fato que gera peculiaridades e limites específicos. Neste sentido, analisou-se o discurso de cento e trinta e três estudantes do curso técnico em agropecuária integrado ao ensino médio, oferecido pelo Instituto Federal de Mato Grosso, campus São Vicente. Desvelou-se que para eles a sociologia serve como apoio a outras disciplinas, oferecendo um conhecimento geral e crítico e percebem a presença desta no currículo como necessária para melhorar as relações interpessoais entre eles e outros atores sociais presentes na instituição escolar, além de propiciar a tolerância de várias culturas, a desinibição necessária para falar em público, se inserir no mercado de trabalho e a transmissão de valores para a formação cidadã.

Palavras-chave: ensino médio técnico, sociologia, juventude do campo.

\begin{abstract}
A study about a looking for a technical high school student to the discipline of sociology

This research aimed to reflect upon the look of the student over the sociology as a school subject. The research subjects are included in the social group of youth from the field, research is qualitative and the data collection instrument is linked to the evaluation process. Thus, it is an investigation produced in the classroom, which is in the observer teacher's field of their practices, a fact that generates specific quirks and limitations. We analyzed the speech of one hundred thirty-three students comprising the integrated technical course in agricultural livestock and the high school, offered by the Federal Institute of Mato Grosso, São Vicente campus. We found out that for them, sociology serves as support to other subjects, providing a general and critical knowledge, and they realize the presence of it in the curriculum as a necessity to improve their interpersonal relationships with other social actors inside the school environment. Besides that, sociology provides tolerance for various cultures, the required disinhibition to speak in public, the insertion in the labor market and the transmission of values to civic education.
\end{abstract}

Keywords: technical high school, sociology, rural youth. 


\section{Introdução}

Como o jovem do campo matriculado em um curso técnico em agropecuária integrado ao ensino médio vê a disciplina de sociologia? O que ele espera dos quarenta e cinco minutos semanais nos quais entrará em contato com conteúdos sociológicos através do processo de ensino e aprendizagem mediado por um professor qualificado para tal? Neste artigo se pretende encontrar respostas a estas questões ao analisar o discurso do próprio grupo social em questão.

A juventude do campo é formada por filhos de assentados, acampados, agricultores familiares (extrativistas, quilombolas, ribeirinhos e demais comunidades tradicionais), camponeses e trabalhadores rurais, e, o olhar deste contingente populacional à finalidade da disciplina de sociologia no currículo do ensino técnico é de fundamental importância até para entender qual a real função do profissional da área de ciências sociais nos Institutos Federais que se expandem em direção ao interior brasileiro.

Durante a história do ensino médio brasileiro, a sociologia foi incluída e rejeitada através de embates ideológicos, políticos e científicos. Ao lembrar a defesa da Sociologia como disciplina por Rui Barbosa em 1870 e a influência positivista na época, a discussão fecunda de Florestan Fernandes sobre o ensino de sociologia na escola secundária brasileira e os debates pósredemocratização, vive-se na atualidade um momento propício para a solidificação desta nos currículos e de produção de materiais didáticos e outros que contemplem o ensino de adolescentes e jovens, pois desde 2008 é obrigatória no ensino médio de formação integrada e com financiamento federal e estadual garantido.

Neste quadro, nota-se que boa parte das pesquisas se debruça sobre o processo de institucionalização da disciplina de sociologia no ensino médio e são pouquíssimas as que tentam discutir os conteúdos, as metodologias e os recursos do ensino, como explicita as Orientações curriculares para o ensino médio - sociologia (MEC, 2006).

Além disso, é importante ressaltar a necessidade de descolonizar o saber e pensar esta disciplina sob um olhar brasileiro e latino-americano, como afirmava Florestan Fernandes em meados da década de 50 (1955, p. 104):

\footnotetext{
"[...] desde o passado colonial e imperial, o ensino humanístico sempre apresentou uma fonte de complexos, de ressentimentos e de atitudes de insegurança dos brasileiros em face das chamadas 'nações cultas'. Esse ensino elaborou e refinou 'sentimentos coloniais', favorecendo a aceitação espontânea de critérios de vida intelectual e de avaliação étnico-cultural que educavam os brasileiros a se subordinarem aos centros culturais estrangeiros ou aos seus representantes."
} 
Por outro lado, ao se ensinar sociologia para adolescentes e jovens deve-se refletir sobre a importância da cultura imagética e da leitura de imagens, filmes e sons que permeiam a realidade deste (a) estudante, intercultural e mundializada. A descentralidade do ser na pósmodernidade (HALL, 2006) requer a formação de atores políticos que atuem tanto nos tradicionais espaços de poder como no ciberespaço e nas redes sociais virtuais.

\section{Rumos e discursos da sociologia no ensino médio nos Institutos Federais}

Para Silva (2007), o ensino de sociologia se insere nos processos de formação, elaboração, disseminação do discurso pedagógico e da organização dos saberes. E, este discurso pedagógico é constantemente influenciado pelas reformas de Estado, fruto das disputas ideológicas, das classes sociais, dos projetos que contam com o planejamento dos intelectuais, das teorias sociais e políticas que levam a uma recomposição constante do campo acadêmico e do campo científico.

Observa-se, segundo Rêses (2004), que o imaginário da população brasileira a cerca da disciplina de sociologia é bastante complexo e variado. Qualifica-se como uma profissão multifacetada, cujo exercício abrange vários nichos mercadológicos, o que permite que a sociedade construa diferentes noções e reputações associadas ao trabalho do sociólogo (NETO et al., 2012) É comum associar o sociólogo a uma espécie de teórico do serviço social. Ou o sociólogo como reformador social, um árbitro de todos os ramos do saber. Há aqueles que vêem este profissional como meramente um coletor de dados estatísticos sobre o comportamento humano, visão que vincula a sociologia à pesquisa de opinião pública. Este último perfil imaginado coloca a sociologia como instrumento de manipulação da classe dominante, e o sociólogo, um cientista impessoal, neutro e imparcial, o que na realidade o inseriria no rol dos burocratas do governo.

Em contraste com estas visões sobre o papel do sociólogo há aqueles que se dedicam a ensinar a sociologia, os licenciados, que ora são chamados a participar dos currículos escolares como verdadeiros emancipadores de mentes e fomentadores da criticidade e autonomia intelectual, ora são excluídos do processo, vistos como disseminadores de um saber subversivo e perigoso para os anseios e ideais de nação hegemônicos, como se vê a seguir: 


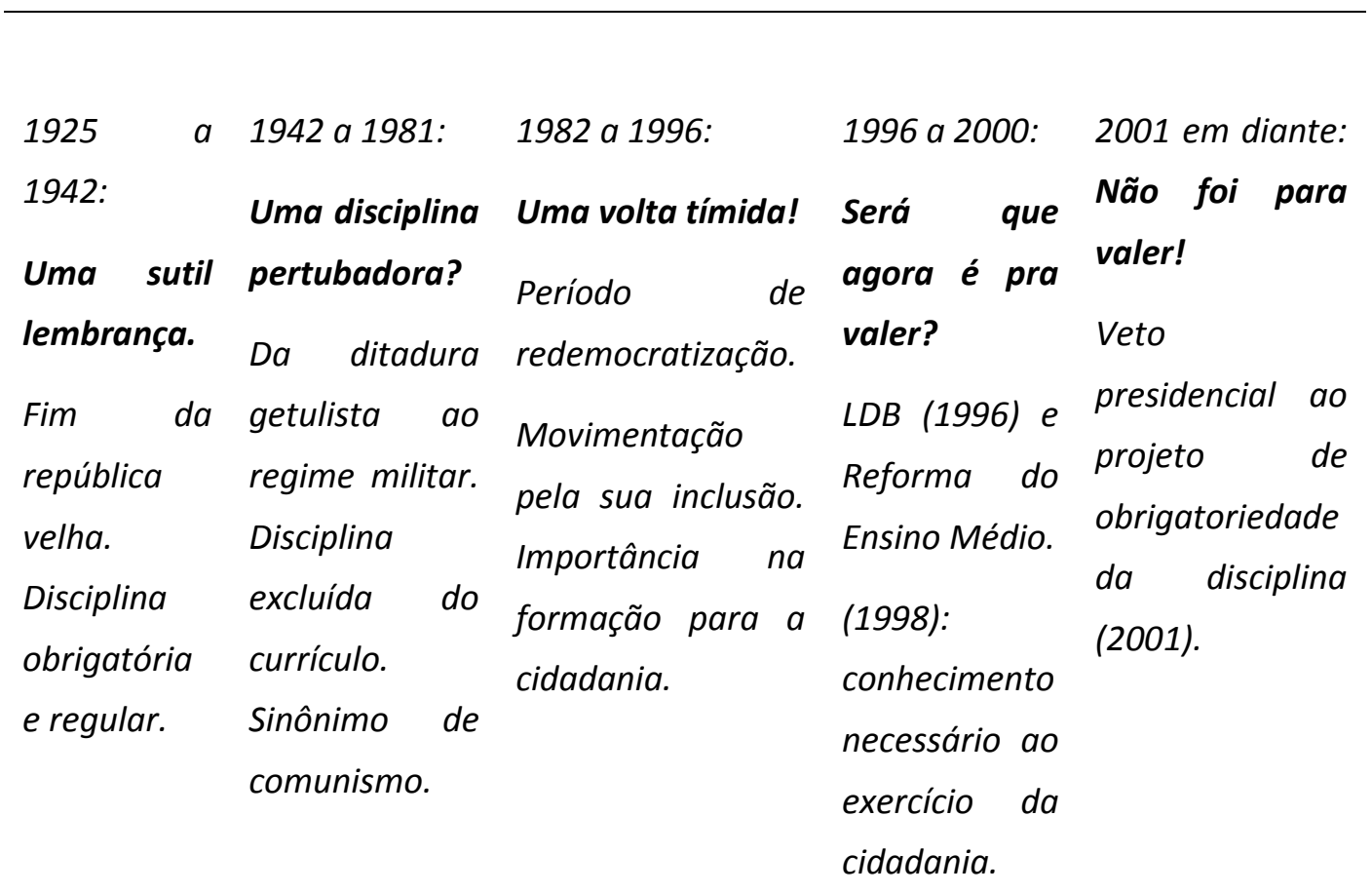

Figura 1- Esquema cronológico sobre a história da sociologia no ensino médio brasileiro. RÊSES, 2004, p. 36.

Acrescenta-se ao esquema cronológico da disciplina de sociologia elaborado por Rêses (2004) o fato de que, em 2 de junho de 2008, é sancionada a Lei 11.684 que altera o artigo 36 da Lei no 9.394, de 20 de dezembro de 1996, que estabelece as diretrizes e bases da educação nacional, para incluir a Filosofia e a Sociologia como disciplinas obrigatórias nos currículos de todas as séries do ensino médio. Para chegar a esta resolução, o campo da educação brasileira foi palco de diversos embates. Como marcos deste processo tem-se as Diretrizes Curriculares Nacionais do Ensino Médio (DCNEM) de 1998, os Parâmetros Curriculares Nacionais do Ensino Médio (PCNEM) de 1999, as Orientações Curriculares no Ensino Médio do MEC de 2004 e as Orientações Curriculares Nacionais do Ensino Médio - Sociologia, de 2006.

Ao pensar o cenário do ensino de sociologia no Brasil nos séculos XX e XXI, conforme Silva (2007), teóricos da sociologia da educação apontam para quatro modelos de currículo produzidos através das disputas dos poderes políticos e científicos dos vários contextos históricos. Um deles é o currículo clássico-científico, fruto da escola liberal republicana e dual. Neste havia a preocupação em formar uma elite capaz de liderar o país. O ensino médio era livresco, com a leitura de textos de sociólogos brasileiros consagrados. O professor era visto com um catedrático portador idéias progressistas e modernizadoras.

O segundo currículo verificado na história é o currículo regionalizado tecnicista, que, afirma Silva (2007), faz parte da escola liberal, autoritária e de profissionalização obrigatória. Aqui 
há a necessidade de formação do capital humano, treinar as novas gerações para constituírem mão-de-obra. O professor é visto como técnico e no ensino médio desvaloriza-se as disciplinas tradicionais, é imediatista e a sociologia enquanto disciplina é excluída do currículo.

A terceira proposta seria o currículo regionalizado por competências, da escola neoliberal, pluralista, flexível, fragmentada e diversificada. Do professor se espera as características de um apresentador de auditório, alguém capaz de divertir e entreter. Nesta tem-se o intuito de formar para empreender e há a adoção de um ensino médio generalista, que também desvaloriza as disciplinas tradicionais e forma para o imediato, para a empregabilidade, para se adaptar a uma sociedade globalizada e capitalista.

Por último, de acordo com Silva (2007), há o currículo científico, adotado pela escola liberal republicana e pela escola unitária, socialista. O professor deve ser aqui um cientista, um pesquisador em primeiro lugar. O currículo apresenta o discurso voltado para a formação do ser humano e a formação é integrada, valoriza as disciplinas, inclusive a sociologia como saber científico.

Não obstante, as orientações veiculadas pelo governo federal sobre a disciplina apontam de forma crítica para estes estudos (2006, p. 104-105):

"Há uma interpretação corrente que, no entanto, deve ser bem avaliada criticamente; ela afirma que a presença ou a ausência da Sociologia no currículo está vinculada a contextos democráticos ou autoritários, respectivamente. No entanto, se se observar bem, pelo menos em dois períodos isso não se confirma, ou se teria que rever o caráter do ensino de sociologia para entender sua presença ou ausência. Entre 1931 e 1942, especialmente após 1937, a sociologia está presente e é obrigatória no currículo em um período que abrange um governo que começa com esperanças democratizantes e logo se tinge de autoritarismo, assumindo sua vocação ditatorial mais adiante. Em outro momento, em plena democracia, o sentido do veto do Presidente da República (2001) à inclusão da Sociologia como disciplina obrigatória traz uma certa dificuldade para esta hipótese."

Novamente obrigatória no ensino médio, a sociologia passa a integrar os currículos das esferas federais, estaduais, municipais, públicas e privadas, garantindo a permanência e consolidação de seus conteúdos na formação do (a) aluno (a) do ensino médio no país. Importante mencionar que, em dezembro deste mesmo ano, é sancionada a Lei 11.892 que institui a Rede Federal de Educação Profissional, Científica e Tecnológica e cria os Institutos Federais de Educação, Ciência e Tecnologia, que nascem com o objetivo, dentre outros, de superar as visões reducionistas sobre o ensino técnico que visam atender apenas uma demanda 
de mercado e propõem atuar como política pública no desenvolvimento local e global de mesorregiões brasileiras (PACHECO, 2009).

Os Institutos Federais que se espalham pelo país a partir da expansão da rede federal são espaços em que a disciplina de sociologia é convidada a interagir com outras disciplinas em currículos que contemplam a vocação produtiva local e as características de cada território, e torna-se assim, indispensável à reflexão da relação entre instituição e comunidade, e entre cursos oferecidos e anseios de grupos sociais e sociedade.

O Plano de Desenvolvimento Institucional construído pelo Instituto Federal de Educação, Ciência e Tecnologia de Mato Grosso para o período 2009-2014 aponta caminhos para a relevância dos conteúdos sociológicos em cursos técnicos quando revela que a missão institucional é (IFMT, 2009, p. 23)

"Proporcionar a formação científica, tecnológica e humanística, nos vários níveis e modalidades de ensino, pesquisa e extensão, de forma plural, inclusiva e democrática, pautada no desenvolvimento socioeconômico local, regional e nacional, preparando o educando para o exercício da profissão e da cidadania com responsabilidade ambiental."

Concomitante a este discurso, no mesmo documento a instituição compromete-se em atingir de forma abrangente os setores econômicos dos segmentos agrário, industrial e tecnológico, de forma a ofertar cursos de acordo com as necessidades culturais, sociais e dos arranjos produtivos do Estado, ao promover a inclusão social, o desenvolvimento sustentável, o empreendedorismo e o associativismo, para levar, através de processos educativos, à geração de emprego e renda.

É preciso também contextualizar o ensino médio integrado à educação profissional, foco deste estudo. Incumbido em lidar com a complexidade do mundo do trabalho e preparar para a vida e regulamentado pelo Decreto no5154 de 2004, esta modalidade é ofertada pelos Institutos Federais com a competência de articular pedagogicamente a formação geral com a qualificação profissional através de uma carga horária aproximada de 3.000 a 3.200 horas/aula e no período mínimo de 3 a 4 anos de duração.

Sendo assim, o ensino de sociologia para os jovens que buscam uma qualificação técnica na área rural deve contemplar a sociologia clássica: Marx, Durkheim e Weber; as discussões centrais da sociologia como imaginação e ciência social, cultura, trabalho, Estado, poder, democracia, violência, participação política e mudança social; dentre outras temáticas, mas também é necessário articular estes conteúdos sociológicos com as demandas provenientes do próprio público-objetivo.

Não se pode, portanto, trabalhar a sociologia com a juventude do campo sem abordar os diferentes movimentos sociais e suas lutas, a questão da juventude campesina e o acesso a R. B. E. C. T., vol 8, núm. 2, mai-ago.2015 ISSN - 1982-873X

DOI: Em andamento. 
direitos. A diversidade étnico-cultural existente no campo e os conflitos econômicos em que estão imersas as comunidades quilombolas, ribeirinhos, descendentes de imigrantes europeus e orientais, e, sociedades indígenas, dentre outras, se inserem no rol de conteúdos imprescindíveis ao ensino de sociologia destinado a este grupo social.

\title{
A juventude do campo e a promessa da sociologia no ensino médio técnico
}

A pesquisa fez o recorte geracional e regional, pois se trata de entender o discurso de estudantes do interior do Mato Grosso e em sua totalidade, jovens. Compreende-se aqui juventude como um grupo social. Sobre o conceito de juventude Margulis (2008, p.11) comenta:

\begin{abstract}
"Conviene ya señalar lãs limitaciones del concepto juventud: esa palabra, cargada de evocaciones y significados, que parece autoevidente, puede conducir a laberintos de sentido si no se tiene en cuenta la heterogeneidad social y las diversas modalidades como se presenta la condición de joven. Juventud es un concepto esquivo, construcción histórica y social y no mera condición de edad. Cada época y cada setor social postula formas de ser joven".1
\end{abstract}

Este autor escreve que as diversas situações sociais e culturais historicamente constituídas impactam nas maneiras de ser jovem, nos modelos que regulam e condicionam a juventude. Ela não se apresenta somente, conforme Margulis (2008), uma modalidade social e cultural dependente da idade, classe e período histórico, mas também é um signo e isso condiciona uma quantidade de atividades produtivas ligadas ao corpo e à imagem e legitima a construção de uma imagem muito singular e ao mesmo tempo mercadológica do que é ser jovem.

A população jovem, que de acordo com o Instituto Brasileiro de Geografia e Estatística (2010) compreende aqueles de 15 a 24 anos, tem especificidades marcantes: são os que efetivamente pressionam a economia para a criação de novos postos de trabalho, são os que mais estão expostos às elevadas taxas de mortalidade por causas externas, por exemplo, a violência, e, são as mulheres jovens que mais contribuem para o nível geral de fecundidade prevalecente no

1 Convém já assinalar as limitações do conceito de juventude: essa palavra, carregada de memória e significados, que parece não dar margem à dúvidas, pode conduzir a labirintos de sentido sem se levar em consideração a heterogeneidade social e as diversas modalidades que se apresentam a condição de ser jovem. Juventude é um conceito esquivo, líquido, construção histórica e social e não mera condição de idade. Cada época e cada camada da sociedade postulam formas de ser jovem. [tradução nossa].

208 DOI: Em andamento.

R. Bras. de Ensino de C\&T 
Brasil. É importante destacar que em 2005 o Brasil implantou espaços formais para tratar da temática, o CNJ - Conselho Nacional de Juventude e a Secretaria Nacional de Juventude, que em 2014 tem como secretária Severine Macedo, que tem o compromisso de atuar em consonância ao Estatuto da Juventude, sancionado pela Lei 12.852, de 2013, que faz o recorte da faixa etária entre 15 e 29 anos como aqueles que podem ser considerados jovens no Brasil.

Apesar de todos estes avanços governamentais em relação à discussão e implementação de ações voltadas para os jovens, a juventude do campo no Brasil ainda sofre com a carência de políticas públicas específicas, como salienta Castro (2009). Esta autora coloca que há precariedade nos serviços públicos e até privados para os jovens rurais no que se refere a espaços de lazer, acesso a transporte e moradia adequada, entre outros. Estigmatizou-se entre estas populações o fato de que morar na zona rural seria sinônimo de morar mal. Assim, estes jovens (CASTRO, 2009, p. 191)::

"Embora não utilizem o termo 'jovem rural', os que se autodenominam jovens constroem sua identidade em diálogo com imagens de um universo rural $e$ espaços 'urbanos', em um 'bricolage', que configura auto-percepções sempre em movimento, através de um diálogo marcado pelo tempo e pelo espaço."

Na contemporaneidade, muitos jovens não querem permanecer no campo, por motivos como precariedade e falta de acesso aos serviços básicos e condições de produção e comercialização dos produtos do trabalho de suas famílias e comunidades, que na lógica do latifúndio e do agronegócio não são vistos como produtores rurais. Segundo Castro (2009, p. 205): "Ficar e sair do campo é mais complexo que a leitura da atração pela cidade, e nos remete à análise de juventude rural como uma categoria social chave pressionada pelas mudanças e crises da realidade do campo."

Assim, é em um ambiente rural bastante dinâmico e permeado por conflitos que nasce o campus São Vicente. É um dos mais antigos do estado, com 71 anos de criação, situa-se às margens da BR 364, km 326, na Vila de São Vicente, na jurisdição do município Santo Antônio do Leverger. É um lugar de natureza exuberante e rica biodiversidade. A escola localiza-se a 86 quilômetros da capital do estado, Cuiabá, e quem passa pela rodovia tem a impressão de observar uma grande fazenda. Logo na entrada há uma frase pintada com letras garrafais "Aprender a fazer, fazendo", o que indica a vocação pragmática do local.

Confirma-se a identidade explicitada acima, quando se observa que é uma instituição de ensino que produz pesquisa e extensão, em sua grande maioria nas áreas de avicultura, suinocultura, piscicultura, agricultura, olericultura, culturas anuais, fruticultura, agroindústria e informática. A instituição também tem núcleos avançados nos municípios de Campo Verde e Jaciara, e oferece cursos de nível médio e superior, licenciaturas, bacharelados, tecnólogos e cursos de qualificação profissional de curta duração. Entretanto, segundo o plano de 
desenvolvimento institucional (2009), pelo menos $50 \%$ das vagas deve ser ofertado para ensino médio técnico, o que corrobora para que o perfil do (a) aluno (a) seja de adolescentes e jovens.

Não obstante, a presença da rodovia e o tráfego intenso de caminhões e carretas impactam profundamente a vivência escolar, dentre eles a constante ocorrência de acidentes próximo à escola, a criminalidade e o acesso fácil a substâncias psicoativas, situações que mobilizam discussões e ações intervencionistas por parte de servidores, discentes e comunidade. A escola tem uma assistente social, uma psicóloga e uma enfermeira, além do departamento de assistência ao discente que possui uma equipe destinada a lidar diretamente com as problemáticas enfrentadas pelos alunos.

Além disso, há a atuação do Grêmio Estudantil, que procura ser um interlocutor dos alunos para com a direção e demais departamentos. A gestão atual foi recentemente re-eleita, numa eleição que contou com a disputa de três chapas. Os alunos desta instituição estão familiarizados com as ferramentas de pressão social, como manifestações e greves, e não raro recorrem a elas para fazer valer seus direitos e buscar melhorias.

Para realização deste estudo de caso optou-se por colher o discurso de estudantes dos primeiros anos do ensino médio. A maioria dos entrevistados reside no alojamento da instituição, sendo oriundos de famílias pertencentes a comunidades rurais de várias localidades do interior de Mato Grosso. Há alguns estudantes semi-internos, moradores de assentamentos, sítios e chácaras próximos à escola. Os sujeitos da pesquisa têm entre 14 e 21 anos e, dos 133 entrevistados, apenas 39 são do sexo feminino.

Neste contexto, pretendeu-se perguntar de forma direta e aberta aos sujeitos da pesquisa, e não utilizar extensivos questionários e entrevistas. Esta pesquisa qualitativa é uma iniciativa da professora de sociologia do campus para entender as percepções dos alunos do que seja a disciplina, seus anseios e o que esperam desta para a sua formação, para aperfeiçoar os planejamentos das aulas e construir algo coerente para seu público-objetivo, que se constitui basicamente por jovens do campo brasileiro do século XXI.

Para tanto, as quatro turmas de primeiro ano existentes no ano letivo de 2013 se depararam, logo na primeira avaliação escrita, com a seguinte pergunta: De que forma você considera que a sociologia pode te auxiliar em sua vida escolar? É importante salientar que transformar a avaliação em um instrumento de coleta de dados possibilita um entendimento muito mais profundo das perspectivas que se pode ter o público objetivo do trabalho docente a ele destinado. Sobre esta escolha metodológica vale observar a sugestão de Osório e Sarandy (2012, p. 160):

\section{"[...], sugerimos que o professor de Sociologia dedique-se, tanto quanto} possivel, a construir práticas de ensino e instrumentos de avaliação orientados pela teoria social e que possam, efetivamente, permitir ao professor perceber 
os resultados de seu ensino nas alterações dos modos de pensar, sentir $e$ avaliar de seus alunos. Seria interessante imaginar instrumentos que se aproximassem das ferramentas intelectuais [...] de modo que metodologias $e$ técnicas de pesquisa social, como a etnografia, a entrevista, a aplicação de questionários, dentre outras, pudessem servir ao professor de Sociologia na investigação acerca dos sujeitos que tem como alunos."

Neste contexto, as respostas foram compiladas e analisadas pela professorapesquisadora, a qual encontrou 14 eixos norteadores do discurso, que apareceram repetidamente nas falas dos (as) educandos (as). A figura abaixo ilustra graficamente as similitudes encontradas:

- Relações Interpessoais

- Conhecimento macro/geral

- Crítica social

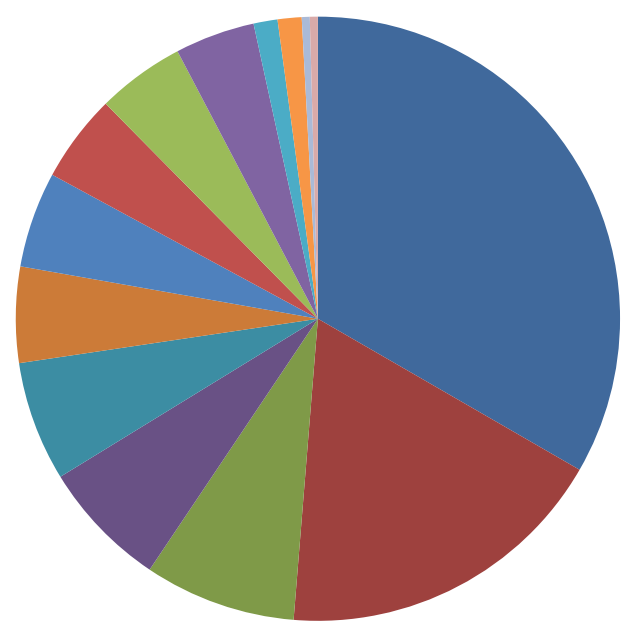

- Tolerância e conhecimento de culturas

- Argumentação/solidez

- Resolução de problemas e enfrentamento de conflitos

Apoio a outras disciplinas

- Formação cidadã

- Sociologia como ciência

- Ver o oculto

- Formação da personalidade

Desinibição

Controle disciplinar

Importante para a juventude

Figura 2 - Gráfico demonstrativo dos eixos norteadores do discurso dos

(as) estudantes sobre a disciplina de sociologia

O que mais aparece nos discursos é a contribuição da sociologia para as relações interpessoais. Setenta e oito estudantes colocaram que a disciplina atuaria diretamente no convívio social, principalmente no microcosmo da escola. Eis algumas falas:

R. B. E. C. T., vol 8, núm. 2, mai-ago.2015 ISSN - 1982-873X

DOI: Em andamento. 
"Melhorar o relacionamento com outras pessoas. Abrir o apetite para alguns assuntos do cotidiano. Sujeito 1

Dentro da sala de aula, pois conforme a gente vai se apresentando, iremos descobrindo novas amizades e refazendo imagens desses amigos. Isso auxilia muito na vida. Sujeito 5

Auxilia no modo de se socializar com as pessoas, a compreendê-las. Ajuda muito também a questionar os porquês da vida. Sujeito 14

A sociologia pode nos ajudar a interpretar assuntos, a compreender a realidade, as diferenças, a aprender a socializar e viver em sociedade perante as desigualdades sociais. Sujeito 21

Para mim ajuda saber viver em sociedade, ter suas escolhas, mas adaptá-las aos outros e a sociedade. Sujeito 45

Me ajuda dentro da sala com o comportamento, modos e tudo o que abrange pessoas em grupos sociais. Sujeito 46

Conviver com as pessoas, me comunicar e também com a sociedade. Sujeito 47 Eu posso mudar o meu jeito de viver na sociedade sem desobedecer regras ou leis, tornando-me uma pessoas sociável. Sujeito 53

Ela vai me ajudar no comportamento na sala e no quarto, sabendo ouvir e saber falar quando necessário, opinando na sociabilidade escolar. Sujeito 55

Ela me ajuda a me comunicar com as pessoas, a ter um melhor convívio na sociedade. Sujeito 57

Pode ser muito importante para a convivência social. Sujeito 62

A sociologia nos ajuda a refletir sobre nossos próprios atos, nos ajuda a interagir com outras pessoas e refletir sobre nós mesmos, sobre o que a gente quer para nossa vida. Sujeito 66

Forma na socialização com as pessoas sem ter racismo e preconceito com elas, e aprender a conviver com elas. Sujeito 67

Pode auxiliar porque ela ajuda a entender melhor todas as mudanças da sociedade e a viver melhor em sociedade. E ela é fundamental para o convívio social que há na escola. Sujeito 75

Fazendo com que eu me socialize com meus colegas podendo discutir algum assunto, assim podendo chegar a algum resultado. Sujeito 82 
Auxilia no meu pensamento, indagar os fatos, ter dúvidas, socializar com os colegas, não ter vergonha, ser aberto, ser participativo, ter interações sociais.

\section{Sujeito 84}

A sociologia pode me ajudar a interagir melhor com as pessoas tipo da minha sala com professores e com a sociedade ao meu redor. Sujeito 85

Aprendendo como cada cultura ou ser se comporta eu consigo assim lidar com cada tipo de pessoa. Sujeito 88

Me ajudando no entrosamento, influenciando a sociedade. Sujeito 91

No meu caso a sociologia pode abrir os meus olhos para a realidade que está acontecendo na sociedade e facilitar a conviver com as outras pessoas e não deixar sozinho ou escondido do mundo e da sociedade. Sujeito 125

Aprende a socializar com outras pessoas e arranjar mais amigos. Sujeito 127

Me ajuda a ter um pensamento mais crítico e aceitar as diversas culturas que estão presentes aqui já que temos alunos de diversos lugares. Sujeito 128

Auxilia na convivência com meus colegas. Sujeito 129

Acho que o fato de estarmos juntos em sala de aula e com outras pessoas nos dá material para entender essa nova sociedade. Sujeito 133"

Convém destacar que o olhar dos estudantes que ingressam no curso médio técnico para a contribuição da sociologia tenta conectar os conhecimentos desta disciplina a uma situação prática, em primeiro lugar. Talvez por este motivo muitos tenham relacionado a disciplina, extremamente teórica, com a capacidade de melhorar as relações interpessoais, atribuindo a esta, uma função imediata, pois precisam lidar com diversos atores sociais no cenário da escola. Palavras como entrosar, convívio, saber falar, interagir melhor, mostram que estes estudantes querem que a sociologia produza mudanças em suas vidas e querem isto em curto prazo.

Também pode-se dizer que as falas convergem, em certo sentido, para a contribuição da sociologia no ensino regular, como salienta Osório e Sarandy (2012, p. 151), “[...] decisiva para a formação da pessoa humana, já que nega o individualismo e demonstra claramente nossa dependência em relação ao todo, [...]."

Em segundo lugar, as falas revelaram a contribuição com o conhecimento macro e geral como papel da disciplina de sociologia. Quarenta e duas respostas incluem esta visão, entre elas:

"Argumentando e enriquecendo mais meu vocabulário, me ajudando a compreender a sociedade onde vivo. Sujeito 23

Pode me auxiliar no conhecimento de mundo, opinar sobre algo para melhorar a sociedade, entre outras. Sujeito 26

R. B. E. C. T., vol 8, núm. 2, mai-ago.2015 ISSN - 1982-873X

DOI: Em andamento. 
Que ela aborda as áreas do convívio humano, desde as relações na família até o comportamento religioso e explica tudo o que acontece na sociedade. Sujeito 39

Pode me fazer entender as antigas sociedades para me situar no presente $e$ buscar entender as futuras gerações. Sujeito 54

A sociologia pode me ajudar a entender os acontecimentos da modernidade $e$ pensamentos. Sujeito 106"

Esta característica atribuída à disciplina é bastante generalizante, inclui até enriquecer o vocabulário e explicar tudo o que acontece na sociedade, mas de certa forma é uma das pretensões da macrossociologia e está presente nos conteúdos do livro didático de sociologia que este estudante recebeu ao início do ano letivo.

Em terceiro lugar aparece nos discursos a crítica social, presente em dezenove respostas. A seguir algumas:

"Ela nos ajuda a questionar as coisas da vida, a encontrar o porquê da vida. Se não houvesse o estudo da sociologia se aceitaria tudo que os outros falassem sem questionar. Sujeito 13

De ter um olhar crítico com relação à sociedade e conhecer a sociedade desde a antiguidade e ter uma idéia de como será futuramente. Sujeito 33

A sociologia auxilia para ver os pontos críticos e reflexivos das coisas. Quando se estuda em grupo é ainda melhor porque você tira a duvida do outro. Sujeito

\section{2}

Ela pode me ajudar a pensar sobre a sociedade de hoje em dia e saber falar, ouvir e questionar e não só obedecer como um escravo moderno. Sujeito $\mathbf{8 0 "}$

A não aceitação das verdades reveladas por meios de comunicação e outros requer a crítica. Atribuir esta característica à disciplina é perceber a possibilidade desta instrumentalizá-los no jogo político-ideológico que precisam participar no cotidiano da pós-modernidade. Para desobedecer é preciso saber o porquê do ato e eles acreditam que a sociologia fornecerá pistas para este entendimento. Mas esta não é uma função apenas da sociologia, mas da instituição enquanto espaço de saber e difusão de conhecimento, como se observa no plano de desenvolvimento institucional do Instituto Federal do Mato Grosso (IFMT, 2009, p. 20):

"Sua função social, como escola pública, alarga-se na medida em que atualmente exige-se das pessoas formação ao longo da vida, o que implica o desenvolvimento de competências geradoras da capacidade de percepção e expressão na qual o cidadão/profissional precisa estar não só atualizado em sua área específica como também em relação ao que está acontecendo em seu

214 DOI: Em andamento.

R. Bras. de Ensino de C\&T 
entorno. Essa concepção de educação inclusiva pressupõe o comportamento crítico e criativo, audacioso desencadeador de ações voltadas à solução de impasses e problemas do cotidiano."

Desta maneira, a disciplina fomenta o pensamento crítico através do exercício da imaginação sociológica e, ao mesmo tempo, a partir da ciência capaz de desconstruir verdades dadas, correntes de opinião, entre outros.

Em quarto lugar, nota-se o tema da tolerância e conhecimento de outras culturas, que aparece em dezesseis falas dos alunos, dentre elas:

"Bom, ela nos ajuda a ter um bom relacionamento com a sociedade, ensinando a respeitar as pessoas. Ensina também sobre a cultura de cada país e ver a vida com outros olhos. Sujeito 38

Pode me auxiliar, ensinando como não agir de forma racista, com preconceito e aprender a viver com as diferenças. Sujeito 63

Convivência com as pessoas, costumes, gírias, línguas e o modo de ensinar dos professores que já aprenderam com a sociedade. Sujeito 68

Para entender melhor as pessoas, entender a relação do ser humano e seus costumes no dia a dia e entender porque o ser humano pensa de formas diferentes. Sujeito 110

Bom, a sociologia ajuda a entender um mundo de diferenças. Sujeito 132"

A coerência dos estudantes com relação à disciplina é evidente, porém é interessante destacar que a sociologia não pode ser tratada apenas por temas, sem o recurso de conceitos e teorias sociológicas, senão corre o risco de banalizar o assunto (MEC, 2006). Aqui se trata de um saber em interface com a antropologia. A construção do conceito de cultura, etnocentrismo, a formação da cultura brasileira e suas matrizes são conteúdos imprescindíveis ao ensino médio técnico.

Em quinto lugar, percebe-se em quinze discursos a contribuição da disciplina para a argumentação e solidez discursiva, como se lê abaixo:

"Tendo mais argumento e auxilia nas outras matérias. Sujeito 6

Ter uma melhor comunicação, ter argumentação, ter uma melhor maneira de pensar sobre a sociedade e ter relações sociais com a comunidade como temos na escola. Sujeito 12

No convívio e no desenvolver de atividades. O preparo para enfrentar certas dificuldades escolares, pois ela expande a mente e melhora o diálogo, principalmente. Sujeito 18

DOI: Em andamento. 
Ajuda a ter um pensamento diferente, mais além e diferente. Ajuda a ver as coisas de uma forma mais clara e a compreender mais sobre a história da humanidade. Sujeito $25^{\prime \prime}$

Realmente, a sociologia é uma disciplina que atua na complexidade do saber e, por este motivo, contribui para enriquecer opiniões, apesar de pretender bem mais que isso, ao construir teorias sociais. Em sexto lugar há a crença de que a disciplina possa atuar na resolução de problemas e enfrentamento de conflitos:

"No meu ponto de vista muda todo o sentido, aprendermos a lidar com as coisas de modo que está acontecendo e a lidar com seus problemas. Sujeito 8 Considero que vai me ajudar a resolver problemas sociais que me afetam.

\section{Sujeito 34}

A sociologia é um estudo de socialização na escola. Pode me ajudar, por exemplo, no melhor entrosamento, união com a turma. Assim podemos nos desenvolver melhor e também nos relacionar com mais qualidade. Sujeito 48"

Também em sexto, com doze falas, está a noção de que a sociologia pode servir de apoio a outras disciplinas. Tanto uma questão quanto a outra trata da sociologia em sua interdisciplinaridade e potencial de interação com o entorno. Ao ser requisitada para resolver conflitos reais, a disciplina adquire uma dimensão teórico-prática interessante para o contexto escolar.

"Na forma de refletir, pois a sociologia nos mostra e ensina muita coisa, além de ser uma disciplina interessante, relaxante e auxiliadora para outras disciplinas. Sujeito 16

A sociologia pode me auxiliar de forma que aprenderei a entender e a conviver melhor em sociedade e assim entenderei melhor as outras disciplinas que a envolvem. Sujeito 30"

Em sétimo lugar aparece a formação cidadã, quase um clichê das ciências humanas e sociais, o qual foi lembrado onze vezes pelos alunos:

"De uma maneira que nós temos que ter igualdade e aprender a socializar com todos que convivem ao nosso redor e aceitar a cultura de cada um. Sujeito 124"

Esta é uma justificativa para a permanência da disciplina de sociologia no ensino médio que é repetida exaustivamente: "formar o cidadão crítico", como apontam as Orientações curriculares para o ensino médio - sociologia (MEC, 2006, p. 105). Além disso, também está inserida na proposta de criação dos Institutos Federais (PACHECO, 2011, p. 29):

216 DOI: Em andamento. 
"O que está posto para os Institutos Federais é a formação de cidadãos como agentes políticos capazes de ultrapassar obstáculos, pensar e agir em favor de transformações políticas, econômicas e sociais imprescindíveis para a construção de outro mundo possivel."

Ainda em sétimo aparece a sociologia como ciência, presente em onze discursos.

"Pensar do ponto de vista das ciências sociais e analisar historicamente e não como um objeto estático a sociedade em que vivemos. Sujeito 64"

Florestan Fernandes considerava o Brasil um país em formação e, dentre as várias vantagens da sociologia inserida como disciplina no currículo do ensino médio estava em "[...] contribuir para preparar as gerações novas para manipular técnicas racionais de tratamento dos problemas econômicos, políticos, administrativos e sociais, [...]" $(1955$, p. 105) que na visão dele seriam extremamente relevantes num futuro próximo.

Neste sentido, a sociologia entrelaçada ao ensino técnico pode proporcionar ao jovem um saber tecnológico voltado aos interesses coletivos e trabalhar em soluções para problemas que atingem multidões e não apenas beneficiem um número reduzido de indivíduos, com poder de compra e privilégios. A tecnologia não apenas para distinguir quem tem acesso ou não, mas para proporcionar uma ponte entre os favorecidos e os que foram atrelados à invisibilidade social.

Em oitavo nota-se em dez discursos a sociologia com capacidade para ver o oculto:

"Ela nos ensina a sermos pessoas críticas, serve para desenvolver nossos pensamentos, para que nos tornemos pessoas críticas que possamos ver um noticiário e ver o que está oculto nele, para que tenhamos perguntas e busquemos respostas. Sujeito 15

A refletir, que leva a perceber em alguns antes desimportantes detalhes, fatos ou frases, de se compreender e compreender as diferenças. Sujeito 19"

Os alunos construíram uma imagem da disciplina muito próxima do que se pensa abordar em sala de aula, a desnaturalização dos fatos como estes são apresentados pela mídia, por exemplo, e o estranhamento do cotidiano do aluno, são momentos interessantes do fazer sociológico. Como aponta Neto (et al., 2012, p. 139) : “O que seria especial nessa prática é o olhar além, ou seja, o olhar por trás dos bastidores, das fachadas, voltado às estruturas ocultas da sociedade." Para estes autores o professor de sociologia auxilia no desvelar das diferenças que formataram a sociedade desigual de hoje.

Em nono está a formação da personalidade e desinibição como finalidade da sociologia em três respostas analisadas: 
"Me ajuda a ser uma pessoa melhor, pensar sobre meus próprios atos, me faz refletir sobre a sociedade em que vivo e outras sociedades também. Sujeito 104

A matéria nos ajuda a nos comunicar melhor com as pessoas e também a perder a vergonha e saber falar. Sujeito 100

Para dialogar mais na sociedade, com os colegas de classe e ter menos vergonha em me apresentar para as pessoas. Sujeito 119"

Tornar as pessoas melhores e menos envergonhadas ao interagirem com outras não é um objetivo essencial da sociologia, mas interessante perceber como isto é relevante para o estudante jovem da área rural. Para eles, a sociologia pode sim ser um meio de transformação do eu, de superação das dificuldades emocionais que aparecem nos espaços que precisam conquistar nesta etapa de suas vidas.

Em décimo, está o controle disciplinar, presente em uma fala e a sociologia como importante para a juventude também lembrada por um sujeito da pesquisa.

"De forma disciplinar, me tornando uma pessoa que se relaciona melhor na sociedade. Sujeito 118

A sociologia ajuda o jovem a ver a realidade que vive com um outro olhar, a refletir as coisas e a pensar a própria vida. Sujeito $2 \mathbf{2 9}^{\prime \prime}$

Este outro olhar é uma das promessas da sociologia. Além destas respostas, houve uma em que a estudante acredita que a sociologia "não contribui", isto é, deixou claro que não vê contribuição alguma da disciplina em questão para sua formação.

Ressalta-se, porém, que estas noções da contribuição da sociologia na visão dos estudantes devem ser observadas como ponto de partida, referências importantes para pensar os conteúdos. Aos poucos estes precisam perceber os limites e possibilidades reais da disciplina e que, apesar de oferecer um conteúdo específico e inovador, este se revestirá de sentido quando o estudante utilizá-lo em benefício de seu próprio esclarecimento e emancipação.

\section{Considerações finais}

Os catorze eixos norteadores do discurso elencados nas falas dos estudantes facilitaram a análise de cada um dos olhares sobre a disciplina de sociologia no ensino médio técnico. Alguns deles eram previsíveis, pois fazem parte do senso-comum da importância da sociologia para sociedade como crítica social e formar para a cidadania. Entretanto, apareceram outras falas sobre a contribuição da sociologia, como no sentido de desinibir o estudante para socializar melhor; ou então, formar a personalidade deste para que se torne uma pessoa adaptável aos 
anseios dos que os rodeiam. Também houve respostas que se aproximaram muito dos objetivos reais da disciplina como tolerância e conhecimento de outras culturas e resolução de problemas e enfrentamento de conflitos sociais.

É certo que os discursos foram reveladores daquilo que se constrói no imaginário do jovem sobre a importância da sociologia. Também mostra uma expectativa estimulante do público objetivo, e, concomitante, geradora de preocupações com o alcance dos resultados almejados diante da pouca carga horária da disciplina, a dificuldade em despir-se do academicismo sem perder a profundidade (NETO et al., 2012), entre outros limites reais do ensino médio técnico.

A sociologia adquire importância nos currículos de ensino médio técnico na medida em que mostra efetiva contribuição na formação do (a) aluno (a). Wright Mills em 1959 afirmava que (1980, p. 12):

"[...] o individuo só pode compreender sua própria experiência e avaliar seu próprio destino localizando-se dentro de seu período; só pode conhecer suas possibilidades na vida tornando-se cônscio das possibilidades de todas as pessoas, nas mesmas circunstâncias em que ele."

Neste sentido, a sociologia para/com o público-objetivo deste artigo, a juventude do campo brasileira, é uma sociologia que pensa políticas para juventude, especialmente para o jovem rural. Este, ao estudá-la, torna-se protagonista de proposições políticas em benefício de coletividades nas quais se insere e que, com estes novos olhares, tem possibilidades reais de influenciar diretamente o Sistema Nacional de Juventude.

O Estatuto da Juventude, capítulo IV, inciso VI, afirma apoiar o jovem trabalhador rural na organização da produção da agricultura familiar e dos empreendimentos familiares rurais, nas ações de (BRASIL, 2013, p. 16-17):

a) estímulo à produção e diversificação de produtos;

b) fomento da produção sustentável baseada na agroecologia, nas agroindústrias familiares, na integração entre lavoura, pecuária e floresta e no extrativismo sustentável;

c) investimento em pesquisa de tecnologias apropriadas à agricultura familiar e aos empreendimentos familiares rurais;

d) estímulo à comercialização direta da produção da agricultura familiar, aos empreendimentos familiares rurais e à formação de cooperativas;

e) garantia de projetos de infraestrutura básica de acesso e escoamento de produção priorizando a melhoria das estradas e do transporte; 
f) promoção de programas que favoreçam o acesso ao crédito, à terra e à assistência técnica rural;

Mesmo com o reconhecimento deste Estatuto pela legislação, sabe-se que a implementação deste só será realidade com a pressão dos movimentos sociais, em especial da juventude. $\mathrm{Na}$ atualidade, estes direitos ainda precisam ser conquistados e a sociologia inserida nos currículos escolares pode instrumentalizar teoricamente o (a) estudante e, com isso, acelerar todo o processo histórico.

\section{Referências}

BRASIL. Estatuto da juventude. 48p. Lei no 12.952, 5 de agosto de 2013.

CASTRO, Elisa Guaraná de. Juventude rural no Brasil: processos de exclusão e a construção de um ator político. Revista Latinamericana de Ciencias Sociales, Niñez y Juventud, v. 7, n. 1, enero/junio, 2009, p. 179-208.

FERNANDES, Florestan. O ensino de sociologia na escola secundária brasileira. In: CONGRESSO BRASILEIRO DE SOCIOLOGIA. 1. 1954: São Paulo. In: Anais. São Paulo: Sociedade Brasileira de Sociologia, 1955, p. 89-106.

HALL, Stuart. A identidade cultural na pós-modernidade. Tradução de Tomaz Tadeu da Silva e Guacira Lopes Louro. 11a ed. Rio de Janeiro: DP\&A, 2006.

IBGE. População jovem no Brasil: a dimensão demográfica. 26p. 2010. Disponível em: http://www.ibge.gov.br/home/estatistica/populacao/populacao jovem brasil/comentario1.pdf Acesso em: 11/04/2014.

IFMT. Plano de Desenvolvimento Institucional, 104p. 2009.

MARGULIS, Mario. La juventud es más que uma palabra: ensayos sobre cultura y juventud. $3^{a} \stackrel{e}{ }$ ed. Buenos Aires: Biblos, 2008.

MEC. Orientações curriculares para o ensino médio. Ciências humanas e suas tecnologias. Secretaria de Educação Básica. v. 3, 133p. Brasília: Ministério da Educação, 2006.

MILLS, Wright. A imaginação sociológica. Tradução de Waltensir Dutra. 5a ed., Rio de Janeiro: Zahar, 1980.

NETO, Euclides Guimarães; GUIMARÃES, José Luis Braga; ASSIS, Marcos Arcanjo de. Educar pela sociologia: contribuições para a formação do cidadão. 1aed., Belo Horizonte: RHJ, 2012. 
OSÓRIO, Adréa; SARANDY, Flávio. Uma conversa sobre avaliação escolar. In: CARNIEL, Fagner; FEITOSA, Samara. (orgs). A sociologia em sala de aula: diálogos sobre o ensino e suas práticas. 1aed., Curitiba: Base, 2012, p. 149-160.

PACHECO, Eliezer. Institutos Federais: uma revolução na educação profissional e tecnológica. In: PACHECO, Eliezer. (org.) Institutos Federais: uma revolução na educação profissional e tecnológica. Brasília: Moderna, 2011, p. 13-32.

. Os Institutos Federais: uma revolução na educação profissional e tecnológica. 25p. Cartilha. Brasília: Ministério da Educação/SETEC, 2009.

RÊSES, Erlando da Silva. ...E com a palavra: os alunos - estudo das representações sociais dos alunos da rede pública do distrito federal sobre a sociologia no ensino médio. 2004, 140p. (Mestrado em Sociologia), Departamento de sociologia da UNB, Brasília, 2004.

SILVA, lleizi Fiorelli. A sociologia no ensino médio: os desafios institucionais e epistemológicos para a consolidação da disciplina. Revista Cronos. Natal - RN, v. 8, n. 2, jul/dez, 2007, p. 403-427.

Silvana Colombelli Parra Sanches - Professora efetiva de ensino básico, técnico e tecnológico do Instituto Federal de Mato Grosso do Sul, campus Nova Andradina, da área de sociologia, email silvana.sanches@svc.ifmt.edu.br 